\title{
Trabalho docente e educação integrada nas escolas técnicas estaduais de Pernambuco*
}

\section{Teacher work and integrated education in state technical High School of Pernambuco}

\author{
Katharine Ninive Pinto Silva** \\ Jamerson Antonio de Almeida da Silva**
}

\begin{abstract}
RESUMO
Apresentamos os resultados de uma pesquisa sobre o processo de implementação do ensino médio integrado em escolas técnicas estaduais da rede de ensino de Pernambuco e as condições de trabalho docente, através de uma pesquisa de avaliação de políticas públicas. A pesquisa foi realizada através da análise documental, entrevistas semiestruturadas e aplicação de questionários, tendo como principais referências os estudos de Freitas, Nosella, Algebaile e outros. Buscamos responder ao seguinte problema: será que a perspectiva de ampliação da jornada escolar no ensino médio não significa também diminuição das condições efetivas de trabalho do professor em relação ao processo de ensino/aprendizagem na perspectiva de uma intensificação do trabalho docente? Concluímos que a ampliação da jornada escolar, no ensino médio das escolas estaduais de Pernambuco, vem acontecendo com a intensificação do trabalho docente, através da pressão por resultados e da perspectiva gerencial adotada. Nas experiências analisadas, a ênfase no reforço escolar, a intensificação do tempo de trabalho e
\end{abstract}

DOI: $10.1590 / 0104-4060.49328$

* 2012-2014 - Jovens e Educação Integral no Ensino Médio: analisando programas em implementação no Estado de Pernambuco, a partir do novo ordenamento legal do Estado Brasileiro (Financiada pelo Conselho Nacional de Desenvolvimento Científico e Tecnológico); 2013-2015 - Trabalho Docente e Educação Integral no Ensino Médio (Financiada pela Fundação de Amparo à Ciência e Tecnologia de Pernambuco); 2014-Atual - Ensino Médio Integral/Integrado e/ou em Jornada Ampliada no contexto da avaliação por resultados - os desafios para o Trabalho Docente (Financiada pelo Conselho Nacional de Desenvolvimento Científico e Tecnológico).

** Universidade Federal de Pernambuco. Centro de Educação. Recife, Pernambuco, Brasil. Av. da Arquitetura, s/n - Cidade Universitária. CEP 50740-550. E-mail: katharineninive@gmail. com; jamersonufpe@gmail.com 
do estudo em sala de aula e o sentimento de encarceramento de docentes e discentes significam um processo de precarização do trabalho docente e da própria escola.

Palavras-chave: Trabalho docente. Ensino médio. Educação integrada.

\begin{abstract}
We present the results of research about the process of implementation of Integrated High School in state technical schools of Pernambuco's educational network and the working conditions of teachers, through public policy evaluation research. The research was conducted through documentary analysis, semi-structured interviews and questionnaires, with the main bibliographical references being the studies of Freitas, Nosella, Algebaile, and others. We seek to answer the following problem: does the prospect of extending the school day in high school also mean a decrease in the effective working conditions of the teacher in relation to the teaching/ learning process, from the perspective of an intensification of the teaching work? We have concluded that the expansion of the school day in high school in the state schools of Pernambuco has been happening with intensification of the teaching work, through pressure for results and the adoption of a managerial point of view. In the experiences analyzed, the emphasis on school reinforcement, the increase in working time and classroom study and the feeling of incarceration of teachers and students are part of a process of precariousness of teaching work and of the school itself.
\end{abstract}

Keywords: Teaching work. High School. Integrated education.

\title{
Introdução
}

De acordo com os estudos de Santos e Oliveira (2009, p. 35), os seguintes elementos "demonstram o peso que tem sido atribuído aos professores no processo de reforma": por um lado, o discurso de que falta preparo aos professores, de que estes têm dificuldades em aceitar novas práticas e frequentemente burlam o sistema, de que existe uma falta de formação inicial e continuada consistente e de que, portanto, a falta de qualidade do ensino se dá devido à ineficiência do professor. Por outro, os professores denunciam os baixos salários, o crescimento da violência no interior das escolas, a precariedade dos estabelecimentos de ensino (em termos de infraestrutura e equipamentos), a burocracia advinda da necessidade de participar da gestão democrática da escola, as permanentes 
mudanças de orientação dos órgãos centrais de ensino, perturbando suas rotinas e suas formas de trabalho, e a falta de suporte nas escolas às atividades docentes.

Considerando essas questões, o nosso estudo buscou responder ao seguinte problema: será que a perspectiva de ampliação da jornada escolar no ensino médio não significa também a diminuição das condições efetivas de trabalho do professor, em relação ao processo de ensino/aprendizagem, na perspectiva de uma intensificação do trabalho docente? E teve como objeto de estudo o trabalho docente no ensino médio integrado em escolas técnicas estaduais da Região Agreste de Pernambuco, com o objetivo geral de analisar as novas condições de trabalho docente nas políticas públicas de educação integrada do ensino médio de Pernambuco, induzidas pelo governo estadual. Para tanto, os objetivos específicos foram: (1) contextualizar as condições de trabalho docente no Brasil e (2) analisar as condições de trabalho docente nas propostas de ensino integrado no ensino médio das escolas públicas estaduais de Pernambuco.

Realizamos o nosso estudo como uma Pesquisa de Avaliação de Políticas Públicas, com foco na implementação de políticas educacionais para o ensino médio, como uma "área de atividade destinada a coletar, a analisar e a interpretar informações sobre a formulação, a implementação e o impacto das ações governamentais que visam alterar as condições de vida da população, em particular dos segmentos sociais mais destituídos (CASTRO, 1989, p. 5). Realizamos uma "avaliação de processos" para avaliar o grau de adequação entre os meios utilizados na implementação e os objetivos definidos na etapa de formulação.

Dentre os procedimentos metodológicos adotados, tivemos a análise documental e a análise de conteúdo a partir da hermenêutica-dialética (MINAYO, 2004) de entrevistas semiestruturadas com 11 sujeitos, sendo 10 docentes das escolas técnicas estaduais (ETEs) e 1 líder sindical.

Os principais documentos analisados foram: o Programa de Modernização da Gestão (PERNAMBUCO, 2008b); Programa de Educação Integral (PEI); Programa Ensino Médio Inovador (ProEMI); Programa de Governo 2011 a 2014 - o novo Pernambuco (FRENTE POPULAR DE PERNAMBUCO, 2010); Plano de Desenvolvimento da Educação (PDE) e Plano de Metas Compromisso Todos pela Educação (2007); Regulamentação do Bônus de Desempenho (Decreto ${ }^{\circ}$ 32.300, de 8 de setembro de 2009); Pagamento de Bônus de Desempenho Educacional - BDE (Decreto n ${ }^{\circ} 33.711$, de 28 de julho de 2009); Alteração do Bônus de Desenvolvimento Educacional - BDE (Lei no 13.696, de 18 de dezembro de 2008); Reordenamento do quadro de recursos humanos nas escolas da rede estadual de ensino de Pernambuco (Portaria $\mathrm{n}^{\circ} 8.290$, de 26 de dezembro de 2011); Responsabilidade Educacional (Lei ${ }^{\circ}$ 13.273, de 05 de julho de 2007); A juventude brasileira ganha nova escola de ensino médio - Pernambuco cria, experimenta e aprova (MAGALHÃES, 2008); Diretrizes Curriculares para o 
Ensino Médio; Diretrizes Curriculares Nacionais para a Educação Profissional de Nível Técnico.

\title{
Trabalho Docente e ampliação da jornada escolar diária no ensino médio
}

Freitas considera que o neotecnicismo está na base das reformas educacionais realizadas na atualidade, fundado na

\begin{abstract}
"teoria da responsabilização", meritocrática e gerencialista, onde se propõe a mesma racionalidade técnica de antes na forma de "standarts", ou expectativas de aprendizagens medidas em testes padronizados, com ênfase nos processos de gerenciamento da força de trabalho da escola (controle pelo processo, bônus e punições). (FREITAS, 2012, p. 382).
\end{abstract}

Esse contexto cria uma certa ambiência para a privatização da educação, porque as políticas de responsabilização buscam expor não só os resultados do desempenho dos alunos das escolas públicas, mas principalmente o próprio sistema educacional público (FREITAS, 2012). Além do investimento em estratégias de redução dos "custos" da educação, sobretudo a partir de medidas de "aceleração da aprendizagem" e da entrada da lógica privada na gestão da educação e da escola, através do gerencialismo, que adquire status de referência de gestão porque se apresenta como um modelo administrativo-gerencial de regulação (HYPOLITO, 2011).

Ao tratarmos da problemática do trabalho docente, podemos identificar, segundo Mancebo (2007, p. 470-471), cinco temas mais recorrentes, são eles: precarização, intensificação do regime de trabalho, flexibilização do trabalho, "descentralização gerencial" e sistemas avaliativos. Sobre intensificação, estudo de Hargreares (1998) - citado por Hypolito, Vieira e Pizzi (2009) - aborda as principais características desse processo, como redução de tempo para qualificação, sensação crônica e persistente de sobrecarga de trabalho, "redução na qualidade do tempo, pois para se 'ganhar' tempo somente o 'essencial' é realizado. Isso aumenta o isolamento, reduzindo as chances de interação" (HYPOLITO; VIEIRA; PIZZI, 2009, p. 105), "soluções" curriculares tecnicistas para compensar a falta de tempo para planejamento, má interpretação desses processos como significando profissionalização. 
De acordo com os estudos realizados por Cabral Neto e Castro (2011), toda a reforma educacional que foi implementada nos últimos tempos teve as mesmas características, sobretudo no que se refere ao ensino médio: focalização de programas - acesso seletivo ao invés de políticas de acesso universal aos direitos sociais e bens públicos, descentralização, privatização - "entendida, no seu sentido mais amplo, como a transferência das responsabilidades públicas para organizações ou entidades privadas"; desregulamentação - que tem como objetivo "diminuir a interferência dos poderes públicos sobre os empreendimentos educacionais privados" (CABRAL NETO; CASTRO, 2011, p. 747).

Um exemplo atual é o da reforma do ensino médio através da Medida Provisória $\mathrm{n}^{\circ} 746$, de 22 de setembro de $2016^{1}$. A medida prevê a ampliação progressiva da carga horária anual do ensino médio para 1400 horas; um currículo centrado em cinco áreas de formação, com Língua Portuguesa, Matemática e Língua Inglesa como obrigatórias, uma carga horária para a Base Nacional Comum Curricular (que ainda não foi aprovada) e uma carga horária para uma das áreas de formação. Também está prevista na medida a possibilidade de trabalhadores com diploma de curso técnico ou superior em área pedagógica ou afim, bem como profissionais com "notório saber", atuarem na docência. A MP também altera a LDB no que diz respeito aos cursos de formação de docentes, estabelecendo um prazo de 2 (dois) anos para a adequação. No entanto, o investimento do governo federal, previsto na Portaria $\mathrm{n}^{\circ} 1145^{2}$, de 10 de outubro de 2016, é bastante limitado em relação ao tempo (no máximo 4 anos), ao número total de escolas e de matrículas e ao valor do financiamento por aluno. Além disso, essa reforma também contribui para a privatização, porque admite a utilização dos recursos para pagamento de bolsas de estudo em instituições privadas, abrindo caminho para as PPPs e para a precarização, pois admite a contratação de professores com "notório saber".

Dentre as questões que já estavam presentes no Projeto de Lei ${ }^{\circ}$ $6.840 / 2013^{3}$ e que também podemos perceber na MP do ensino médio estão: a tendência a uma organização curricular por áreas de conhecimento, inclusive buscando influenciar a formação inicial; a tendência ao aumento da jornada escolar também no ensino médio, buscando "qualificar" a juventude para uma futura (e cada vez mais postergada) entrada no mundo do trabalho; a compreensão de que o ensino médio deverá garantir a opção (ou perspectiva de que se está tendo opção) de uma inserção no mercado de trabalho direta, sem que o

1 https://www.planalto.gov.br/ccivil_03/_Ato2015-2018/2016/Mpv/mpv746.htm

$2 \mathrm{http} / /$ pesquisa.in.gov.br/imprensa/jsp/visualiza/index.jsp?jornal $=1 \&$ pagina $=23 \& \mathrm{da}$ ta $=11 / 10 / 2016$

$3 \mathrm{http}: / /$ www.camara.gov.br/proposicoesWeb/fichadetramitacao?idProposicao $=602570$ 
trabalhador tenha que obter a profissionalização no ensino superior e a sutil referência à necessidade de uma parceria com a iniciativa privada, sobretudo na educação profissional.

\section{Trabalho docente e ensino médio integrado na rede estadual de Pernambuco}

Dois Programas Federais que estão diretamente relacionados à ampliação do número de escolas e de matrículas no Programa de Educação Integral (PEI), implementado pelo governo do estado de Pernambuco nas Escolas de Referência em Ensino Médio (EREMs) e nas ETEs, são o Programa Ensino Médio Inovador (ProEMI) e o Programa Brasil Profissionalizado, ambos compondo o Plano de Desenvolvimento da Educação (PDE). O ProEMI foi criado a partir da Portaria $\mathrm{n}^{\circ}$ 971, de 9 de outubro de 2009, com o objetivo de apoiar e fortalecer o desenvolvimento de propostas curriculares inovadoras nas escolas do ensino médio não profissional, voltado para a "melhoria da qualidade do ensino médio não profissionalizante" (BRASIL, 2009, p. 7). O Programa Brasil Profissionalizado tem como objetivo fortalecer as redes estaduais de educação profissional e tecnológica, através do repasse de recursos do governo federal para que os estados invistam em suas escolas técnicas, permitindo a modernização e a implementação das redes públicas de educação profissional e tecnológica.

De acordo com Dutra (2014, p. 23), o PEI foi "criado com a finalidade de reestruturar o Ensino Médio", através do reordenamento da rede estadual de Pernambuco, criando as EREMs e as ETEs. Ainda de acordo com Dutra (2014), o PEI se fundamenta na filosofia da Educação Interdimensional elaborada por Costa $(2008)^{4}$. Mas, de acordo com o autor, a essa perspectiva vem se somar o planejamento estratégico baseado na Tecnologia Empresarial Odebrecht (TEO) e nos quatro pilares da educação contidos no Relatório Jacques Delors, transformada por Ivaneide Lima (2011) em Tecnologia Empresarial Aplicada (TEAR) à Educação, cuja proposta é realizar o planejamento estratégico aplicado às escolas, com a obrigação das mesmas em elaborar um Plano de Ação Educacional.

De acordo com Dutra (2014), do ponto de vista curricular, as ETEs ofertam a Educação Profissional Integrada ao ensino médio, mas também nas

4 Mais informações: http://www.dersv.com/EDUCACAO\%20INTERDIMENSIONAL. pdf. Acesso em nov. 2016. 
modalidades concomitante e subsequente. A rede estadual de ensino de Pernambuco conta atualmente com 28 ETEs, incluindo a ETE de Criatividade Musical ${ }^{5}$.

De acordo com dados do $\mathrm{CNTE}^{6}$, a rede estadual de Pernambuco não cumpre a Lei do Piso quanto ao valor, assim como outras doze redes de ensino estaduais, além de ser a segunda rede estadual que pior remunera os professores com nível superior ${ }^{7}$. Também tem uma carreira limitada, pois o valor pago ao professor sem nível superior é o mesmo pago ao professor com nível médio. E, já com as vantagens, a remuneração é apenas dois reais superior ao Piso Nacional do Magistério. Para os professores que atuam nas EREMs e ETEs, há um incentivo através de uma Gratificação de Localização Especial ${ }^{8}$, que está congelada, desde 2008, em $\mathrm{R} \$ 2.032,00$ (dois mil e trinta e dois reais) para os professores das EREMs com jornada integral de 40 horas e $\mathrm{R} \$ 1.623,00$ (um mil, seiscentos e vinte e três reais) para os professores das EREMs com jornada parcial de 32 horas. Somando o valor da remuneração do professor, considerando a proporcionalidade para 40 horas, mais a gratificação da jornada integral de 40 horas, o salário deste fica ainda inferior ao praticado por outras sete redes estaduais (Pará, Amazonas, Distrito Federal, Roraima, Maranhão, Tocantins, Mato Grosso do Sul).

A maioria dos docentes entrevistados das ETEs citou uma carência de recursos didáticos e de manutenção dos equipamentos: "[...] ainda precisa que o Governo do Estado melhore a entrega do livro didático e a manutenção dos equipamentos de mídia, que você vê que têm muitos equipamentos, mas quando se quebra, não se retorna e a gente precisa de utilizar e não tem." (ETEBE2).

Sobre a relação do PEI com as condições de trabalho docente nas ETEs, os entrevistados consideram que a principal questão é o sentimento de encarceramento, que tanto os docentes quanto os discentes sentem, sobretudo em função da grande quantidade de horas de trabalho em sala de aula: "O problema é a quantidade de hora aula que você tem que dar. [...] Você chega aqui com o sol nascendo e sai com o sol se pondo." (ETEBE4).

A maioria dos entrevistados avaliou positivamente a proposta das ETEs, considerando que este seria um padrão de qualidade que deveria ser universalizado:

5 No site do governo do estado de Pernambuco, http://www.educacao.pe.gov.br/ portal/?pag=1\&men=71, acesso em novembro de 2016 .

6 http://www.cnte.org.br/index.php/tabela-salarial.html, acesso em novembro de 2016.

7 A partir da tabela do CNTE, fizemos uma equiparação do valor da maior remuneração informada de cada rede estadual para $40 \mathrm{~h}$, já que em cada rede de ensino o valor informado é diferenciado, entre $20 \mathrm{~h}$ e $40 \mathrm{~h}$.

$8 \mathrm{http}$ //legis.alepe.pe.gov.br/arquivoTexto.aspx?tiponorma=1\&numero=12965\&complem ento $=0 \&$ ano $=2005 \&$ tipo $=\&$ url $=$ 
Eu acho que é uma boa. Escola que é um padrão de qualidade de muito bom. Queria que fosse para todos os estudantes do Estado. Ele é uma escola diferenciada, então o meu negócio é igualdade. Então, eu acho que todo aluno do Estado, aluno de escola pública, deveria ter uma escola desse tipo aqui. (ETEBE1).

No entanto, boa parte dos entrevistados considerou que há um processo de intensificação dos estudos dos alunos, com o aumento da jornada escolar diária e o currículo conteudista:

Eu não sei se teríamos como aliviar a carga dos meninos, porque eles têm as disciplinas da grade regular, mas têm as disciplinas técnicas que vêm em maior número, por ser escola técnica. Mas a quantidade de disciplinas é tão grande! Juntando tudo isso, que eles ficam sobrecarregados demais. Eu sei o que nós poderíamos fazer para amenizar isso e logo. Logo os terceiros também terão estágio. Então a tendência é ficar mais puxado ainda. (ETEGR3).

O dualismo na oferta do ensino médio, tratado por Nosella (2015), também pode ser reconhecido através da análise das entrevistas. Por um lado, a oferta é caracterizada por uma falta de equidade entre escolas "diferenciadas" como as ETEs e as demais escolas da rede. Mas, por outro, foi identificada uma falta de equidade das próprias escolas "diferenciadas" entre si. E, o mais interessante, é que não foi recorrente a alusão a uma necessária ampliação das condições "diferenciadas" para as demais escolas da rede. Talvez, já considerando aquilo que os estudos de Algebaile (2009) indicam em relação à ampliação sem qualidade que vem sendo feita na educação brasileira, gerando uma escola pobre para os pobres, os entrevistados tenham um temor de que uma maior ampliação signifique uma maior precarização das condições. Inclusive porque identificam essa ampliação da precarização no movimento de ampliação do número de escolas atendidas até o momento.

\section{Considerações finais}

Concluímos que existe um processo de precarização do trabalho docente no Brasil, por um lado, caracterizado pela desvalorização da profissão docen- 
te, acarretada pelos baixos salários e pela desconsideração da importância da profissão docente do ponto de vista social, acarretando uma fuga dos jovens em relação à profissão docente. No caso da rede estadual de Pernambuco, essa situação é bem pior, visto que os salários estão muito defasados, inclusive comparando-os com redes municipais de ensino do próprio estado, sem contar com o desequilíbrio entre professores concursados e contratados.

Por outro, hoje o contexto do trabalho docente, no Brasil, é marcado por uma política educacional neoliberal, gerencialista, que tem sua perspectiva de qualidade de educação fundada na avaliação por resultados e no ranqueamento das escolas e das redes de ensino a partir de uma ênfase no processo de accountability ou responsabilização. Além de tornar precário o trabalho docente, essa perspectiva contribui para a sua intensificação, visto que são somadas às atribuições docentes, além da cobrança por melhores resultados, a comprovação e a prestação de contas numa perspectiva produtivista. Pernambuco vem sendo referência nacional e internacional neste tipo de política.

De uma forma geral, os entrevistados avaliam que a ampliação da jornada diária no ensino médio nas ETEs vem se dando sobretudo em busca da melhoria do IDEB, bem como para formação para o trabalho. Entre os entrevistados, essa proposta vem sendo avaliada positivamente, a não ser pelo fato de que é considerado que há uma sobrecarga de trabalho tanto para os docentes quanto para os discentes, chegando a provocar uma sensação de encarceramento em todos. Mesmo assim, a tese de que mais tempo na escola é igual a maior aprendizagem dividiu as opiniões dos entrevistados, pois, para alguns, fora da escola os adolescentes não se dedicariam aos estudos e, para outros, a ênfase apenas na sala de aula não acarreta em maior aprendizagem, inclusive porque falta o tempo necessário para que os alunos desenvolvam seus estudos e faltam o espaço e as atividades necessárias para uma formação mais integral deles. Mas, para todos os entrevistados, em relação ao trabalho docente, faltam tempo e espaço para que possam planejar e estudar para melhorar a qualidade do ensino.

Dessa forma, concluímos o nosso estudo considerando que os resultados indicam que há um processo, em curso, de implementação de políticas de ampliação da jornada escolar e/ou de realização de uma educação integral/ integrada, centrado em uma lógica neoliberal que intensifica e torna precário o trabalho docente, ao trazer para o cenário escolar novas atribuições: proteção e guarda de adolescentes e jovens; expectativas em torno da garantia da empregabilidade em um cenário de desemprego estrutural; melhoria dos indicadores sociais do país através de resultados em avaliações standards e da melhoria do fluxo escolar e da certificação. 


\section{REFERÊNCIAS}

ALGEBAILE, E. Escola pública e pobreza no Brasil: a ampliação para menos. Rio de Janeiro: Lamparina, 2009.

BRASIL. Lei $n^{\circ}$ 9.394, de 20 de dezembro de 1996. Diretrizes e Bases da Educação Nacional (LDB). Educação profissional: legislação básica. Brasília, DF: PROEP, 1996.

BRASIL. Resolução CNE/CEB nº 3, de 26 de junho de 1998. Brasília, DF, 1998.

BRASIL. Resolução CNE/CEB $n^{\circ}$ 4, de 1999. Brasília, DF, 1999.

BRASIL. Parecer CNE/CEB nº 39, de 2004. Brasília, DF, 2004.

BRASIL. Decreto $n^{\circ}$ 6.094, de 24 de abril de 2007 - Plano de Metas Compromisso Todos pela Educação. Brasília, DF, 2007.

BRASIL. Lei $n^{\circ} 11.892$, de 29 de dezembro de 2008. Institui a Rede Federal de Educação Profissional, Ciência e Tecnologia, cria os Institutos Federais de Educação, Ciência e Tecnologia e dá outras providências. 2008.

BRASIL. Portaria $n^{\circ}$ 971, de 9 de outubro de 2009. Brasília, DF, 2009.

BRASIL. Resolução CNE/CEB $n^{\circ}$ 2, de 30 de janeiro de 2012. Brasília, DF, 2012.

BRASIL. Estudo sobre a Lei do Piso Salarial. Brasília, DF: MEC/CNE/CEB, s/d.

CABRAL NETO, A.; CASTRO, A. M. D. A. Gestão escolar em instituições de ensino médio: entre a Gestão Democrática e a gerencial. Revista Educação e Sociedade, Campinas, v. 32, n. 116, p. 745-770, jul./set. 2011.

CASTRO, M. H. G. Avaliação de programas e políticas sociais. Cadernos de Pesquisa $n^{\mathbf{0}}$ 12. Núcleo de Estudos de Políticas Públicas. Universidade de Campinas - UNICAMP, Campinas, SP, 1989.

DUTRA, P. Educação integral no ESTADO de Pernambuco: uma política pública para o Ensino Médio. Recife: Editora UFPE, 2014.

FREITAS, L. C. de. Os reformadores empresariais da educação: da desmoralização do magistério à destruição do sistema público de educação. Revista Educação e Sociedade, Campinas, v. 33, n. 119, p. 379-404, abr./jun. 2012.

FRENTE POPULAR DE PERNAMBUCO. Programa de Governo Eduardo Campos (2011-2014). 2010. Disponível em: <http://psbpe.org.br/site-2010/wp-content/uploads/ plano_governo2011-2014.pdf>. Acesso em: 01 jul. 2013.

HYPOLITO, A. M. Reorganização gerencialista da escola e trabalho docente. Educação: Teoria e Prática, v. 21, n. 38, out./dez. 2011. 
HYPOLITO, A. M.; VIEIRA, J. S.; PIZZI, L. C. V. Reestruturação curricular e autointensificação do trabalho docente. Currículo sem Fronteiras, v. 9, n. 2, p. 100-112, jul./ dez. 2009.

MANCEBO, D. Agenda de Pesquisa e opções teórico-metodológicas nas investigações sobre trabalho docente. Revista Educação e Sociedade, Campinas, v. 28, n. 99, p. 466-482, maio/ago. 2007. Disponível em: <http://dx.doi.org/10.1590/S010173302007000200009>. Acesso em: 8 nov. 2016.

MINAYO, M. C. S. O desafio do conhecimento: pesquisa qualitativa em saúde. 8. ed. São Paulo: Hucitec; Rio de Janeiro: Abrasco, 2004.

NOSELLA, P. Ensino Médio - unitário ou multiforme? Revista Brasileira de Educação, v. 20 , n. 60 , jan./mar. 2015.

PERNAMBUCO. Lei $n^{\circ} 13.486$, de $1^{\circ}$ de julho de 2008. Institui o Bônus de Desempenho da Educação - BDE. 2008a.

PERNAMBUCO. Lei Complementar $n^{\circ} 125$, de 10 de julho de 2008. Cria o Programa de Educação Integral e dá outras providências. 2008b.

PERNAMBUCO. Decreto $n^{\circ} 32.300$, de 08 de setembro de 2008. Regulamenta a Lei ${ }^{\circ}$ 13.486/2008, que institui o BDE. 2008c.

PERNAMBUCO. Decreto $n^{\circ} 33.711$, de 28 de julho de 2009. Dispõe sobre o pagamento do Bônus de Desempenho Educacional - BDE e dá outras providências. 2009.

SANTOS, L. L. de C. P.; OLIVEIRA, D. A. A Intensificação do trabalho docente e a emergência de nova divisão técnica do trabalho na escola. InterMeio: Revista do Programa de Pós-Graduação em Educação, Campo Grande, MS, v. 15, n. 29, p. 32-45, jan./jun. 2009.

Texto recebido em 21 de novembro de 2016. Texto aprovado em 09 de fevereiro de 2017. 
